\title{
The Jejunal Absorption of Glucose Oligomers in the Absence of Pancreatic Enzymes
}

\author{
BENNY KERZNER, ${ }^{12: i}$ HOWARD R. SLOAN, GERALD HAASE, H. JUHLING MCCLUNG, AND \\ ANTON H. AILABOUNI \\ Ohio State University, Department of Pediatrics. Children's Hospital, 70) Children's Drive, Columbus, Ohio, USA
}

\begin{abstract}
Summary
We compared the absorption of carbohydrate from solutions of glucose oligomers and glucose in jejunal Thiry-Vella fistulae, a preparation deprived of pancreatic secretions. The studies were performed with two concentrations $(90$ and $360 \mathrm{mg} / \mathrm{dl}$ ) of both glucose and the glucose oligomers. Carbohydrate absorption from glucose solutions $(33.1 \pm 2.8,115.9 \pm 8.9 \mu \mathrm{g} / \mathrm{cm} / \mathrm{min})$ was significantly greater $(P<0.025 ; P<\mathbf{0 . 0 0 5})$ than that from oligomer solutions $(26.6 \pm 2.1$ and $92.4 \pm 9.0 \mu \mathrm{g} / \mathrm{cm} / \mathrm{min})$. Thin-layer analyses of the perfusates demonstrate digestion of oligomers with a chain length up to eleven and suggest digestion of oligomers of even greater chain length. Atrophy of the jejunal mucosa occurred over the course of the study as evidenced by a decrease in the ratio of villous height to crypt depth from 3.8 to 0.3 , and by a $80 \%$ decrease in the activity of maltase, sucrase, and lactase. Atrophy was accompanied by a significant decline in the absorption of both glucose oligomers $(P<0.005)$ and glucose $(P<0.01)$ from the more concentrated solutions but the decrement in absorption of both carbohydrates was similar: glucose oligomers, $79.3 \pm 19.4$ $\mu \mathrm{g} / \mathrm{cm} / \mathrm{min}$; and glucose, $69.8 \pm 14 \mu \mathrm{g} / \mathrm{cm} / \mathrm{min}(P>0.20)$. Water absorption was enhanced by both carbohydrates, but there was no demonstrable difference between solutions of glucose and glucose oligomers. The osmolality of the solutions clearly influenced water absorption $(P<0.025)$ but failed to effect the absorption of carbohydrates.
\end{abstract}

\section{Speculation}

In patients with pancreatic insufficiency, solutions of glucose oligomers with low osmolality may provide an adequate source of calories. Although glucose is better absorbed than glucose oligomers from a short segment of jejunum, the length of the small intestine should be adequate to compensate for this difference. The absorption of the glucose oligomers may be a function of polymer length and therefore studies with subfractions separated according to chain length will demonstrate which oligomers are most efficiently absorbed. Such information may provide the theoretical basis for the construction of an ideal carbohydrate supplement for patients with pancreatic insufficiency.

Polysaccharides are readily available nutrients with high caloric density, properties which have encouraged their incorporation into both infant formulae (19) and supplemental feeding regimens for patients with pancreatic insufficiency (3). In normal infants, there is evidence that the assimilation of starch is suboptimal in the first 6 months of life, a period in which pancreatic amylase activity is limited. Auricchio et al. (2) observed that feeding starch to infants in this period resulted in jejunal accumulation of glucose oligomers with a chain length greater than thirty. In the newborn, there is only a limited rise in blood sugar during starch tolerance tests ( 1 ), and those fed a high percentage of their calories as starch may grow slowly and develop diarrhea $(17,20)$.

Partially hydrolyzed starch (oligomers of glucose) may be effec- tively assimilated because the intestinal brush border enzyme, glucoamylase, has maximal activity against polymers with an average chain length of five to nine glucose units (14). We therefore designed our studies to determine the ability of the jejunum to digest and absorb glucose oligomers in the absence of pancreatic amylase. In Thiry-Vella fistulae, intestinal preparations devoid of pancreatic secretions, we compared glucose oligomer absorption with that of glucose.

\section{MATERIALS AND METHODS}

\section{PREPARATION OF ANIMALS}

Jejunal Thiry-Vella fistulae were constructed in seven 3-wk-old Yorkshire piglets (18); two died and were excluded from the study. Starting $20 \mathrm{~cm}$ distal to the ligament of Treitz. we isolated a $35 \mathrm{~cm}$ segment of jejunum with its blood supply intact. Five $\mathrm{cm}$ were removed for later analyses. Both ends of the remaining $30 \mathrm{~cm}$ were exteriorized through the anterior abdominal wall where stomata were fashioned, and the residual jejunum was anastomosed. In preparation for the perfusion studies, the animals were trained to remain suspended in slings. At the conclusion of the perfusion studies, the fistulae were excised. A portion was processed for histology, and from the remaining tissue, the mucosa was scraped, homogenized, and immediately frozen.

\section{PERFUSION STUDIES}

To compare absorption from glucose and glucose oligomer solutions, we initiated a series of perfusion studies, at 10-day intervals, starting on the fifth postoperative day. At that time, the fistula should be free of pancreatic amylase because the half-life of brush border disaccharidases is less than $18 \mathrm{hr}(13)$, and normally villus enterocytes of intact pig jejunum turn over in less than $48 \mathrm{hr}(4)$. A total of 27 studies were completed: 15 in the first $3 \mathrm{wk}$ (early studies) and 12 in the last $3 \mathrm{wk}$ (late studies). Each of these studies was divided into five perfusion periods in which either D-glucose (Fisher Scientific; reagent grade) at a concentration of 90 or $360 \mathrm{mg} / \mathrm{dl}$, glucose oligomers (Polycose: Ross Laboratories) at a concentration of 90 or $360 \mathrm{mg} / \mathrm{dl}$, or mannitol at $360 \mathrm{mg} / \mathrm{dl}$ was infused. The mannitol period was used as a control for the measurement of passive water absorption. To measure the effect of tonicity we adjusted, in consecutive studies, the osmolality of each set of five solutions to either 200 (hypotonic) or 300 (isotonic) mOsm/liter. All solutions contained PEG $4000(\mathrm{lg} / \mathrm{dl})$, potassium $(5 \mathrm{mEq} / \mathrm{liter})$ and bicarbonate $(20 \mathrm{mEq} / \mathrm{liter})$. The isotonic set of solutions contained sodium (135 mEq/liter) and chloride (120 mEq/liter), whereas the hypotonic set contained sodium ( $85 \mathrm{mEq} /$ liter) and chloride (70 mEq/liter). Appropriate amounts of mannitol were added to the solutions to adjust their tonicity to either 200 or $300 \mathrm{mOsm} /$ liter. The $\mathrm{pH}$ of all solutions was adjusted to 7.2 .

To perform the studies, foley catheters were introduced into the proximal and distal stomata of the fistula which was flushed with 
$50 \mathrm{ccs}$ of warm saline to remove stagnant contents. Perfusion solutions were warmed to $37^{\circ} \mathrm{C}$ and infused at a constant rate with the aid of a peristaltic pump (Harvard model 600-000). In accordance with the suggestions of Fox et al. (9), we selected a flow rate of $3.4 \mathrm{ml} / \mathrm{min}$. In preliminary experiments, carbohydrate absorption was reproducibly measured with an equilibration period of $20 \mathrm{~min}$ and a collection time of $15 \mathrm{~min}$, and this schedule was therefore followed in all subsequent studies. Samples were selected for infusion in random order. The perfusates were collected on ice and then immediately frozen at $-20^{\circ} \mathrm{C}$ until the time of analysis.

\section{ANALYTICAL METHODS}

We compared the normal jejunum obtained at the time of fistula construction with the fistula excised at the conclusion of the study. Villus height and crypt depth of appropriately oriented tissues were measured with an ocular screw gauge micrometer. The activities of maltase, sucrase, and lactase were determined by the method of Dahlquist (5).

The carbohydrate content of perfusion solutions was estimated by the $O$-toluidine method after hydrolysis with sulfuric acid and trichloroacetic acid (15). The carbohydrate content of samples applied to thin layers was determined by the phenol-sulfuric acid method (7). PEG 4000 was measured by the turbidometric method of Hayden (11). The net water and carbohydrate absorption during a perfusion period were calculated on the basis of the change in the concentration of PEG 4000, the nonabsorbed marker. The carbohydrate oligomer profile of test solutions, both before and after perfusion, was evaluated by chromatography on thin layers of silica gel $\mathrm{G}$. Two $\mathrm{ml}$ samples were deionized by passage over a five $\mathrm{ml}$ column of a mixed-bed resin (Amberlite MB3). Ten to $50 \mathrm{mg}$ of carbohydrate were applied as $5 \mathrm{~mm}$ streaks onto thin-layer plates which were then thoroughly dried. The plates were developed with ethyl acetate:methanol:water, 104:72: 26 , and stained with an anisaldehyde reagent $(12,16)$. Quantitation of the oligomers in the starch hydrolysate was determined by highperformance liquid chromatography on ion-exchange resins (21).

To evaluate the possibility that there might be bacterial amylase activity in the perfusate, we passed the mannitol control solution through the fistulae and incubated the recovered solution with glucose oligomers. Equal volumes of the perfusate and a 1\% solution of glucose oligomers were incubated at $37^{\circ} \mathrm{C}$. Thin-layer analyses of the incubation solutions failed to demonstrate progressive hydrolysis of the oligomers even after $24 \mathrm{hr}$.

The perfusion data were evaluated by a three-way analysis of variance. The variables considered were the type of carbohydrate, its concentration, and the osmolality of the perfusion solution. Where appropriate a two-tailed paired $t$ test was performed.

\section{RESULTS}

As listed in Table 1, both glucose and glucose oligomers are absorbed from the fistula, but glucose was absorbed more efficiently than glucose oligomers $(P=0.029$ by three-way analysis of variance). Carbohydrate absorption was not influenced by the tonicity of the perfusion solutions $(P=0.858)$, and the analysis of variance suggested an interaction between carbohydrate concentration and absorption. The data from the isotonic and hypotonic experiments were therefore pooled for analyses of carbohydrate absorption by the paired $t$ test. Figure 1 depicts the difference between glucose and glucose oligomer absorption by the fistula from solutions with carbohydrate concentrations of 90 and 360 $\mathrm{mg} / \mathrm{dl}$. The absorption of glucose polymer was $73 \%$ that of glucose $(P<0.005)$ from the $90 \mathrm{mg} / \mathrm{dl}$ solution and $83 \%(P<0.001)$ from the $360 \mathrm{mg} / \mathrm{dl}$ solution. The total absorption of carbohydrate, from solutions of both glucose and glucose oligomers, was significantly greater from the more concentrated solutions $(P=0.001)$ even though the percentage absorbed from solutions of both concentrations was similar.

Glucose oligomers stimulated water absorption from both iso-

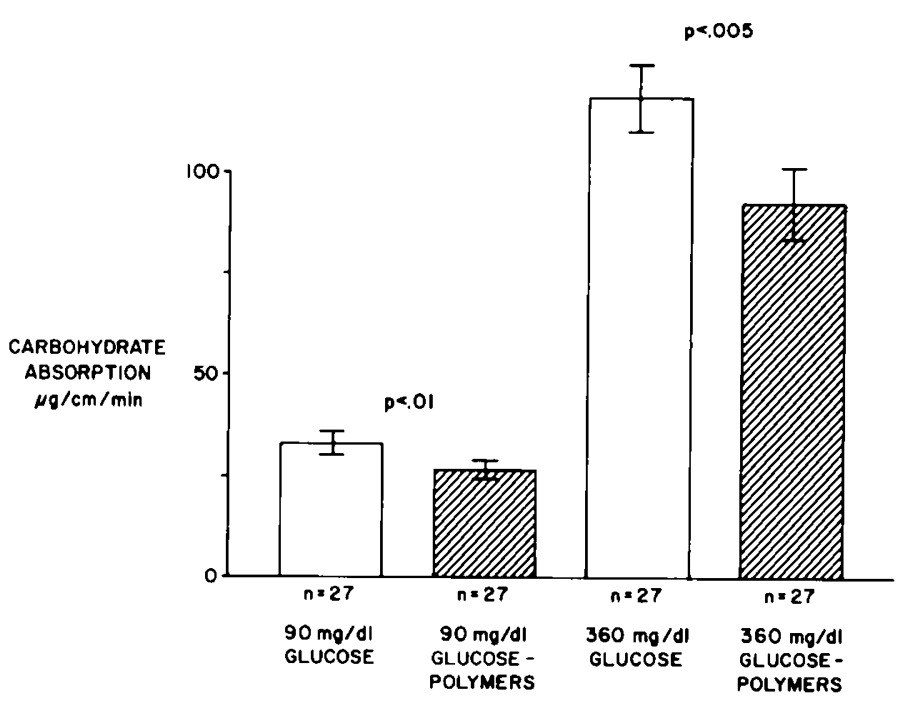

Fig. 1. Carbohydrate absorption from Thiry-Vella fistulae. The absorption from perfusates containing either 90 or $360 \mathrm{mg} / \mathrm{dl}$ of glucose or glucose-polymers is compared.

Table 1. Carbohydrate absorption by Thiry-Vella fistulae

\begin{tabular}{|c|c|c|c|c|}
\hline & fusion solution & & & \\
\hline $\begin{array}{c}\text { Carbohydrate } \\
\text { type }\end{array}$ & $\begin{array}{l}\text { Carbohydrate } \\
\text { concentration } \\
(\mathrm{mg} / \mathrm{d} \mathrm{l})\end{array}$ & $\begin{array}{c}\text { Osmolality } \\
\text { (mOsm/liter) }\end{array}$ & $\begin{array}{c}\text { Carbohydrate } \\
\text { absorption } \\
(\mu \mathrm{g} / \mathrm{cm} / \mathrm{min})\end{array}$ & $n$ \\
\hline Glucose & 90 & $\begin{array}{l}200 \\
300\end{array}$ & $\begin{array}{l}32.6 \pm 3.06^{2} \\
33.5 \pm 4.68\end{array}$ & $\begin{array}{l}13 \\
14\end{array}$ \\
\hline Glucose oligomers & 90 & $\begin{array}{l}200 \\
300\end{array}$ & $\begin{array}{l}27.2 \pm 3.38 \\
26.0 \pm 2.71\end{array}$ & $\begin{array}{l}13 \\
14\end{array}$ \\
\hline Glucose & 360 & $\begin{array}{l}200 \\
300\end{array}$ & $\begin{array}{l}116.9 \pm 14.14 \\
115.0 \pm 11.60\end{array}$ & $\begin{array}{l}13 \\
14\end{array}$ \\
\hline Glucose oligomers & 360 & $\begin{array}{l}200 \\
300\end{array}$ & $\begin{array}{l}94.0 \pm 12.04 \\
91.4 \pm 13.92\end{array}$ & $\begin{array}{l}13 \\
14\end{array}$ \\
\hline
\end{tabular}

1 Three way analyses of variance demonstrated that the absorption of glucose was significantly greater than glucose oligomers $(P=0.029)$. Increasing the carbohydrate concentration of the solutions markedly enhanced absorption $(P=0.001)$, but alterations in the osmolality did not significantly alter carbohydrate uptake $(P=0.858)$.

Mean \pm S.E. 
Table 2. Water absorption by Thiry-Vella fistulae

\begin{tabular}{|c|c|c|c|c|c|}
\hline \multicolumn{3}{|c|}{ Perfusion solution } & \multirow[b]{2}{*}{$\begin{array}{c}\text { Water } \\
\text { absorption } \\
(\mu \mathrm{l} / \mathrm{cm} / \mathrm{min})\end{array}$} & \multirow[b]{2}{*}{$\begin{array}{l}\text { Carbohydrate- } \\
\text { stimulated } \\
\text { water } \\
\text { absorption } 2\end{array}$} & \multirow[b]{2}{*}{$n$} \\
\hline $\begin{array}{c}\text { Carbohydrate } \\
\text { type }\end{array}$ & $\begin{array}{c}\text { Carbohydrate } \\
\text { concentration } \\
(\mathrm{mg} / \mathrm{dl})\end{array}$ & $\begin{array}{c}\text { Osmolality } \\
\text { (mOsm/liter) }\end{array}$ & & & \\
\hline None (control) & 0 & $\begin{array}{l}200 \\
300\end{array}$ & $\begin{aligned}-0.11 & \pm 0.06^{3} \\
0.03 & \pm 0.07\end{aligned}$ & & $\begin{array}{l}13 \\
14\end{array}$ \\
\hline Glucose oligomers & 90 & $\begin{array}{l}200 \\
300\end{array}$ & $\begin{array}{l}0.13 \pm 0.07 \\
0.24 \pm 0.07\end{array}$ & $\begin{array}{l}0.24 \pm 0.07 \\
0.21 \pm 0.05\end{array}$ & $\begin{array}{l}13 \\
14\end{array}$ \\
\hline Glucose & 90 & $\begin{array}{l}200 \\
300\end{array}$ & $\begin{array}{l}0.09 \pm 0.06 \\
0.20 \pm 0.07\end{array}$ & $\begin{array}{l}0.20 \pm 0.06 \\
0.18 \pm 0.08\end{array}$ & $\begin{array}{l}13 \\
14\end{array}$ \\
\hline Glucose oligomers & 360 & $\begin{array}{l}200 \\
300\end{array}$ & $\begin{array}{l}0.17 \pm 0.06 \\
0.30 \pm 0.08\end{array}$ & $\begin{array}{l}0.28 \pm 0.05 \\
0.27 \pm 0.07\end{array}$ & $\begin{array}{l}13 \\
14\end{array}$ \\
\hline Glucose & 360 & $\begin{array}{l}200 \\
300\end{array}$ & $\begin{array}{l}0.22 \pm 0.05 \\
0.45 \pm 0.11\end{array}$ & $\begin{array}{l}0.34 \pm 0.06 \\
0.43 \pm 0.08\end{array}$ & $\begin{array}{l}13 \\
14\end{array}$ \\
\hline
\end{tabular}

'Three way analyses of variance confirmed that absorption of water was significantly influenced by the osmolality of the solvents $(P=0.007)$, by the concentration of the carbohydrate $(P=0.025)$, but not by the type of sugar used $(P=0.525)$.

${ }^{2}$ The increment in water uptake (above the basal level) that is induced by carbohydrates.

${ }^{3}$ Mean \pm S.E.

tonic and hypotonic solutions (Table 2). The extent of water movement in response to glucose is not significantly different from that induced by the glucose oligomers $(P=0.525)$. Water absorption is greater from solutions with the higher concentration of carbohydrate $(360 \mathrm{mg} / \mathrm{dl})$ and the lower osmolality $(200 \mathrm{mOsm} /$ liter) $(P=0.025 ; P=0.007)$. The extent of carbohydrate-stimulated water movement from both isotonic and hypotonic solutions is similar.

The predominant carbohydrates in the glucose oligomer solutions, as determined by high-performance liquid chromatography, are maltohexaose [degree of polymerization (DP), 6], 12.7\% and maltaheptaose (DP, 7), 10.4\%. It contains $1.6 \%$ glucose and $39.9 \%$ oligomers with a DP $>11$. Thin-layer analyses of the oligomercontaining solutions recovered from the fistulae demonstrate a consistent change in the distribution of oligosaccharides (Fig. 2). There is a profound decrease in the intensity of the bands with $R_{f}$ 0.23 (DP, 6) and 0.18 (DP, 7) and also of the band at the origin which represents sugars with a DP greater than eleven. There was a striking increase in the band with an $R_{f}$ of 0.69 (glucose, DP, 1 ). Mannitol, which was added to solutions to achieve appropriate tonicities, has an $R_{f}$ of 0.59 which is only slightly greater than that of maltose which has an $R_{f}$ of 0.58 . Mannitol, however, stains turquoise and is superimposed on the dark blue maltose band. There is also an unstained area in the center of the blue band at the origin, which probably represents small amounts of salt.

We compared the appearance and the enzyme profile of the jejunal mucosa before fistula construction and after excision of the fistula. Villus atrophy was evident in the fistula. The ratio of villus height to crypt depth decreased from 3.8 to $0.3(P<0.005)$. Disaccharidase activity decreased: maltase, $96.6 \pm 23.7$ to $28.6 \pm$ $7.3(P<0.01)$; sucrase, $44.3 \pm 10.1$ to $24.6 \pm 8.0(P<0.01)$; lactase, $15.4 \pm 1.1$ to $8.0 \pm 1.1(P<0.005)$. To evaluate the effects of these atrophic changes, we compared the absorption of carbohydrates in "early" versus "late" studies. Both glucose and polycose absorption decreased as the fistulae aged. From perfusion solutions with a carbohydrate concentration of $90 \mathrm{mg} / \mathrm{dl}$ glucose absorption decreased by $14.2 \pm 4.8 \mu \mathrm{g} / \mathrm{cm} / \mathrm{min}$ and glucose oligomers decreased by $13.4 \pm 5.1 \mu \mathrm{g} / \mathrm{cm} / \mathrm{min}$, respectively, whereas from the $360 \mathrm{mg} / \mathrm{dl}$, solutions the decrease was $69.8 \pm 14.0$ and $79.3 \pm 19.4$, respectively. At both carbohydrate concentrations the reduction in oligomer absorption was not significantly different from that of glucose $(P>0.2)$.

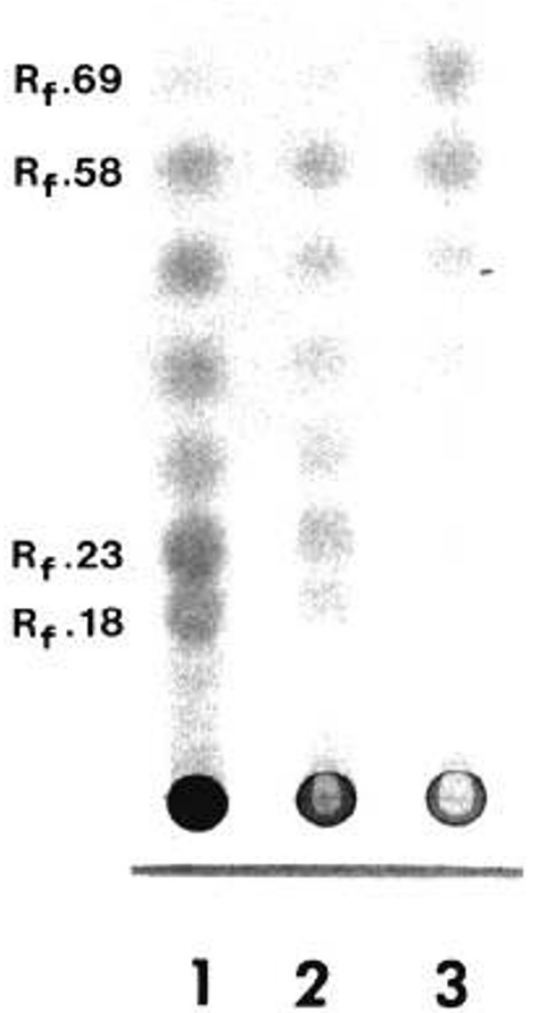

Fig. 2. Thin-layer separation of glucose oligomer solutions. Lane $/$, glucose oligomers, $1000 \mathrm{mg} / \mathrm{dl}$. Lane 2 glucose oligomers, $360 \mathrm{mg} / \mathrm{dl}$. before infusion. Lane 3, glucose oligomers post infusion. Solvent, ethyl acetate:methanol:water, 104:72:26. The $R_{f} \mathrm{~s}$ of glucose. maltose, maltohexaose, and maltoheptaose are $0.69,0.58,0.23$, and 0.18 , respectively. 


\section{DISCUSSION}

Our data indicate that in a limited segment of jejunum, free of pancreatic amylase, glucose is absorbed more efficiently than glucose oligomers. Oligomers with a DP less than six comprise $29.5 \%$ of the glucose oligomers used in this study. Because less than $20 \%$ of the infused glucose oligomers are absorbed, it seemed possible that the uptake of carbohydrate was confined to these relatively short-chain oligomers. Thin-layer chromatographic analyses of the fluid recovered from the fistulae, however, show that rather than an exclusive digestion of short-chain material, both long (DP $>11$ ) and intermediate- (DP, 6 and 7) chain oligomers are digested and that significant amounts of glucose are actually generated. With the solvent used in our thin-layer system, oligomers above DP 11 remain at the origin, and it is, therefore, not possible to determine the degree of digestion of the large constituents.

The fact that glucose is absorbed more efficiently than glucose oligomers suggests that digestion is the rate-limiting step in oligomer uptake. The uptake of carbohydrates, however, is a complex process which also involves diffusion through the unstirred water layer, binding to specific receptors and transport into the cell (10). It is possible that glucose oligomers diffuse into the unstirred water layer more slowly than glucose. The generation of large amounts of glucose from glucose oligomers in the lumen of the fistula (Fig. 2), however, means that more glucose is formed than can be absorbed. Because less carbohydrate is absorbed from oligomer solutions than from equivalent glucose solutions, we assume that lower concentrations of glucose are achieved in the unstirred water layer when oligomers are perfused. It is also conceivable that oligomers compete for glucose receptor sites on the brush border surface. During the course of atrophy, the percentage decreases in glucose and oligomer absorption are similar. This observation indicates that available surface area is a more important determinant of oligomer absorption than is the activity of relevant brush border enzymes.

We compared carbohydrate absorption from solutions with equal concentrations by weight of glucose and glucose polymers. Because hydrolysis of $100 \mathrm{mg}$ of glucose oligomers produces approximately $111 \mathrm{mg}$ of glucose due to incorporation of water, the glucose oligomer solutions contained more potential moles of hexose than did the glucose solutions of the same weight concentration. Had we used isocaloric concentrations of glucose and glucose polymers, the observed discrepancy between their absorption might have been greater.

In contrast to both Klish (15) and Daum (6), we find that water absorption from glucose and glucose oligomer solutions is similar. Our use of solutions of equal tonicity to make this comparison probably accounts for the apparent discrepancy. It seems reasonable to compare solutions of equal osmolality because the tonicity of ingested solutions, regardless of their composition, is rapidly readjusted in the stomach and duodenum (8). Furthermore, varying the osmolality by $100 \mathrm{mOsm}$ results in only a marginal increase in water uptake.

Although the Thiry-Vella fistula is a convenient model for the study of digestion and absorption in the absence of pancreatic secretions, it obviously differs from the in vivo situation. The fistula is not exposed to foods or to salivary, gastric, or duodenal secretions. It does, however, permit an insight into the jejunum's ability to assimilate oligosaccharides. Our studies suggest that although the absorption of glucose is greater than that of glucose oligomers, the absolute difference is small, indicating that adequate carbohydrate calories would be provided by the ingestion of oligomers even in the absence of pancreatic amylase.

\section{REFERENCES AND NOTES}

I. Anderson. T. A.. Foman, S. J., and Filer, L. J.: Carbohydrate tolerance studies with 3-day old infants. J. Lab. Clin. Med., 74: 31 (1972).

2. Auricchio, S.. Della Pietra. D.. and Vegnente, A.: Studies of intestinal digestion of starch in man. II. In infants and children. Pediatrics, 39: 853 (1967).

3. Berry. H. K.. Kellogg. F. W.. Jung. M. M.. Ingberg. R. L.. Richter, L.. and Gutjahr, C.: Dietary supplement and nutrition in children with cystic fibrosis. Am. J. Dis. Child., 129: 165 (1975).

4. Butler, D. (i., Gall, D. G.. Kelly, M. H., and Hamilton, J. R.: Transmissable gastroenteritis: mechanisms responsible for diarrhea in an acute viral enteritis in pigiets. J. Clin. Invest.. 53: 1335 (1974)

5. Dahlquist. A.: Method for assay of intestinal disaccharidases. Anal. Biochem., 7: 18 (1964).

6. Daum. F., Cohen. M. I., McNamara. H., and Finberg. L.: Intestinal osmolality and carbohydrate absorption in rats treated with polymerized glucose. Pediatr. Res.. 12: 24 (1978).

7. Dubois. M.. Gilles, K. A.. Hamilton, J. K.. Rebers, P. A., and Smith, F.: Colormetric method for determination of sugars and related substances. Anal. Chem.. 28: 350 (1956).

8. Fordtran, J. S.. and Locklear. T. W.: Ionic constituents and osmolality of gastric and small intestinal tluids after eating. Am. J. Dig. Dis., 11: 503 (1966).

9. Fox, J., Care. A. D., and Swaminathan, R.: The use of a Thiry-Vella loop of jejunum to study the intestinal absorption of calcium and inorganic phosphate in the conscious pig. Br. J. Nutr., 39: 431 (1978).

10. Gray, G. M.: (Carbohydrate digestion and absorption: role of the small intestine. N. Engl. J. Med.. 292: 1225 (1975).

11. Hyden, S.: A turbidometric method for determination of higher polyethylene glycol in biological materials. Upsala K. Lantbr. Annaler., 22: 139 (1956).

12. Huber, C. N.. Scobell, H.. and Tai. H.: Determination of saccharide distribution of corn syrup by direct densitometry of thin-layer chromatograms. Cereal Chem.. 43: 342 (1966).

13. James, W. P. T.. Alpers, D. H.. Gerber, J. E.. and Isselbacher, H. J.: The turnover of disaccharidases and brush border proteins in rat intestine. Biochim. Biophys. Acta. 230: 194 (1971).

14. Kelly. J.. and Alpers. D.: Properties of human intestinal glucoamylase. Biochim. Biophys. Acta, 315: 113 (1973).

15. Klish. J., Rodriguez., J. T.. Udall. J. N.. Rogers, J. H.. and Nichols, B. L.: The effects of intestinal solute lead on water secretion in acquired monosaccharide intolerance. Pediatr. Res. 10: 356 (1976).

16. Kwiterovich. P. O., Sloan. H. R., and Frederickson. D. S.: Glycolipids and other lipid constituents of normal human liver. J. Lipid Res.. 11: 322 (1970).

17. Lilibridge. (. B., and Townes, P. L.: Physiologic deficiency of pancreatic amylase in infancy: A factor in iatogenic diarrhea. J. Pediatr.. 82: 279 (1973).

18. Pekas. J. C.: Preparation of and glucose absorption from intestinal loops in conscious swine. J. Anim. Sci., 46: 729 (1977).

19. Ross Laboratory package insert for Similac 24

20. Safety and suitability of modified food starches for use in baby foods. The Sub committee on the Evaluation of the Safety of Modified Starches in Infant Foods, Committee on Nutrition. (American Academy of Pediatrics, Houston, 1977).

21. The authors express our gratitude to Larry Cummings of Bio Rad Laboratories. Richmond, CA, and Henry Scobell of A.E. Staley Company. Decatur. IL. for determining by high-pressure liquid chromatography the oligosaccharide profile of the glucose oligomers.

22. The authors are grateful to Constance Seckel for her technical assistance, to Brenda Gaffney and Rita Compston for preparation of this manuscript and to Dr. Larry Sachs for performing the computerized analyses of variance:

23. Requests for reprints should be addressed to: Benny Kerzner, M.D., Department of Pediatrics, Columbus Children`s Hospital. 700 Children`s Drive. Columbus, OH 43205 (USA).

24. This research was supported by grants $74-175$ and $74-228$ from Columbus Children's Hospital Research Foundation and grant 74-203 from Ross Laboratories.

25. Received tor publication rebruary 5,1980

26. Accepted for publication June 13,1980. 